\title{
Pregnancy Induced Hypertension Accompanied With Anemia: Potential Stunting of Newborns
}

\author{
Rumelia L. Sembiring ${ }^{1,2}$, Nasrudin A. Mappaware ${ }^{1,3}$, Elizawarda ${ }^{2,4}$, Yusrawati Hasibuan ${ }^{2}$ \& Andi Nilawati ${ }^{5,6}$ \\ ${ }^{1}$ Postgraduate Program, Department of Midwifery, Hasanuddin University, Makassar, South Sulawesi, Indonesia \\ ${ }^{2}$ Department of Midwifery, Medan Polytechnic of Health Sciences, Medan, North Sumatera, Indonesia \\ ${ }^{3}$ Faculty of Medicine, Indonesia Muslim University, Makassar, South Sulawesi, Indonesia \\ ${ }^{4}$ Human Resource Education and Training Unit, Department of Midwifery, Medan Polytechnic of Health Sciences, \\ Medan, North Sumatera, Indonesia \\ ${ }^{5}$ Hallal Center for Public Health Research, Faculty of Public Health, Hasanuddin University, Makassar, South \\ Sulawesi, Indonesia \\ ${ }^{6}$ Faculty of Public Health, Mandala Waluya College, Kendari, Southheast Sulawesi, Indonesia \\ Correspondence: Rumelia L. Sembiring, Postgraduate Program, Department of Midwifery, Hasanuddin \\ University, Makassar, South Sulawesi, 90245, Indonesia: Tel: 62-813-9604-5555. E-mail: \\ rumelia.lubina@yahoo.co.id
}

Received: April 20, 2018 Accepted: May 10, 2018 Online Published: May 18, 2018

doi:10.5539/gjhs.v10n6p164 URL: https://doi.org/10.5539/gjhs.v10n6p164

\begin{abstract}
Introduction: Pregnancy induced hypertension (PIH) of anemia pregnant women is a major contributor to adverse birth outcomes of newborns. This research aims to assess the association between pregnancy induced hypertension of anemia pregnant women and poor birth outcomes of newborns, especially body length of newborns at delivery.
\end{abstract}

Material and Methods: One hundred and eight pregnant women are enrolled according to the inclusion criteria. Sociodemographic data, anthropometric measurements, obstetric profiles (gravida), and data of systolic and diastolic blood pressure were collected in this study. Trained midwives drew blood samples from pregnant women as the study samples to measure their hemoglobin $(\mathrm{Hb})$ concentrations and to assess their anemia. Gestational age (GA), types of delivery, anthropometric measurements of newborns (length, weight, head circumference, abdominal circumference and chest circumference) were conducted at delivery. Univariate and bivariate linear analyses were conducted to compare birth outcomes of newborns for each group

Results: Of the total 108 pregnant women as the study samples, 25 pregnant women had blood pressures at normal level and normal $\mathrm{Hb}$ concentrations, 36 pregnant women had pregnancy induced hypertension (PIH), 29 pregnant women had anemia and 18 pregnant women had pregnancy induced hypertension (PIH) of anemia pregnant women respectively. All groups showed significantly different characteristics of pregnant women in terms of age $(p=0,027)$, height $(p=0,019)$, weight $(p=0.000)$, body mass index (BMI) $(p=0,001)$, Hb concentration $(p=$ $0.000)$, systolic blood pressure $(p=0.000)$, diastolic blood pressure $(p=0.000)$. Mean length of newborns was significantly lower in pregnancy induced hypertension $(\mathrm{PIH})$ with anemia pregnant women $(p=0.001)$. Statistical tests showed that there were negative correlations between maternal Hb concentrations and birth length $(p=0.024)$ as well as blood pressure and birth length $(p=0.000)$.

Conclusion: The average length of newborns in pregnancy induced hypertension (PIH) and pregnancy induced hypertension $(\mathrm{PIH})$ of anemia pregnant women was statistically significant shorter length (stunting) than the normal group. Thus, it is suggested that women who give birth with these conditions should pay more attention to the intake of good nutrition in the first 5 years of their children (the gold period) to prevent long-term adverse effects.

Keywords: pregnancy induced hypertension, anemia, outcomes, newborn stunting

\section{Introduction}

Pregnancy induced hypertension (PIH) of anemia pregnant women are always associated with the risk of poor outcomes of newborns at delivery including body length that less than normal which called stunting $(<47 \mathrm{~cm})$ 
(Kheir, Ali, \& Kononna, 2014; Melamed et al., 2014; Gaur, Kataria, \& Agarwal, 2015; Sabah, Ali, \& Adiba, 2015; Patricia Medeiros Falcao et al., 2016; Saiki, Mie, \&Garovic, 2016). Pregnancy induced hypertension (PIH) and its complications occur in $10 \%$ of pregnancies wordwide and are commonly foundatover 20 weeks gestational age with maternal blood pressures at $\geq 140 / 90 \mathrm{mmHg}$ (Roberts et al., 2012; Melamed et al., 2014; Kolluru, Harika, \& Kaul, 2016; Patricia Medeiros Falcao et al., 2016; Saiki, Mie, \& Garovic, 2016; Zhang et al., 2017; Ahmed et al., 2018; Berhe et al., 2018). WHO reported that anemia showed adverse effects to half of all pregnant women, $52 \%$ in developing countries and 23\% in developed countries (Ghimire \& Ghimire, 2013; Madaan et al., 2013; Kaur et al., 2015; Manthan, 2015; Satyam and Khushbu, 2015; Asrie, 2017; Siddiqui et al., 2017; Feleke and Feleke, 2018; Singh and Kaur, 2018). Anemia is a condition in which $\mathrm{Hb}$ concentration is less than $11 \mathrm{gr} / \mathrm{dl}$ and its concentration might increase the risk of pregnancy up to fivefold (Gaur, Kataria and Agarwal, 2015; Perry et al., 2018; Chowdhury et al., 2015; Pels \& Ganzevoort, 2015; Sabah, Ali, \& Adiba, 2015; Asrie, 2017; Siddiqui et al., 2017; Feleke \& Feleke, 2018; Singh \& Kaur, 2018). Poor conditions of maternal health during pregnancy that include pregnancy induced hypertension (PIH) and anemia are the main indicators of poor outcomes of newborns, including stunting in newborns(Ghimire \& Ghimire, 2013; Chowdhury et al., 2015; Gaur, Kataria,\& Agarwal, 2015; Kaur et al., 2015; Manthan, 2015; Sabah, Ali \& Adiba, 2015; Satyam \& Khushbu, 2015; Asrie, 2017; Siddiqui et al., 2017; Tunkyi \& Moodley, 2017; Rogozińska et al., 2017; Singh \& Kaur, 2018; Feleke \& Feleke, 2018; Ye et al., 2014; Bilano et al., 2014; Kheir, Ali, \& Kononna, 2014; Endeshaw \& Berhan, 2015; Muti et al., 2015; Irwinda, Raymond, \& Nembo, 2016; Kolluru, Harika, \& Kaul, 2016; Khader et al., 2017; Parmar \& Vaja, 2017; Ahmed et al., 2018; Berhe et al., 2018). Studies that attempt to investigatepoor outcomes of newborns from mothers with pregnancy induced hypertension (PIH) is accompained with anemia during pregnancy are scarce. Therefore, the authors are interested to assess the potential stunting of newborns in pregnant women who have the condition.

\section{Materialsand Methods}

\subsection{Design of the Study and Sample Population}

In this prospective cross-sectional study, association between maternal blood pressure(BP) and $\mathrm{Hb}$ concentrations(third trimester) with birth outcomes of newborns were assessed for normal tension, PIH, anemia and PIH is accompanied with anemia. Flowchart of the study is indicated in Figure 1. All pregnant women were screened from June until December 2017from Sitti Khadijah 1 Hospital for Mother and Child Health Makassar, South Sulawesi, Indonesia. 108 pregnant women were scereened by health officers according to the inclusion criteria that include singleton gestation, planned delivery at the same hospital and willingness to participate. Exclusion criteria were determined for pregnant women who had history of preterm delivery, obstetric complication, chronic hypertension and other medicalcomplications. Pregnancy induced hypertension (PIH)was classified according to systolic and diastolicblood pressures; normal blood tension $(<140 / 90 \mathrm{mmHg})$ and pregnancy induced hypertension $(\mathrm{PIH})(\geq 140 / 90 \mathrm{mmHg})$, whereas, conditions of anemia were classified intoboth non-anemia $(>11 \mathrm{gr} / \mathrm{dL})$ and anemia $(\leq 11 \mathrm{gr} / \mathrm{dL})$ based on $\mathrm{Hb}$ concentrations. Consent formswere signed by pregnant woman who had willingness to participate after the explanation of the study. The total 108 pregnant women were enrolled that consisted of 25 respondents with normal blood pressurewithout anemia, 36 respondents with pregnancy induced hypertension (PIH)without anemia, 29 respondents with normal blood pressure with anemia and 18 respondents with pregnancy induced hypertension (PIH)with anemia were sampledusingthe purposive sampling method. 


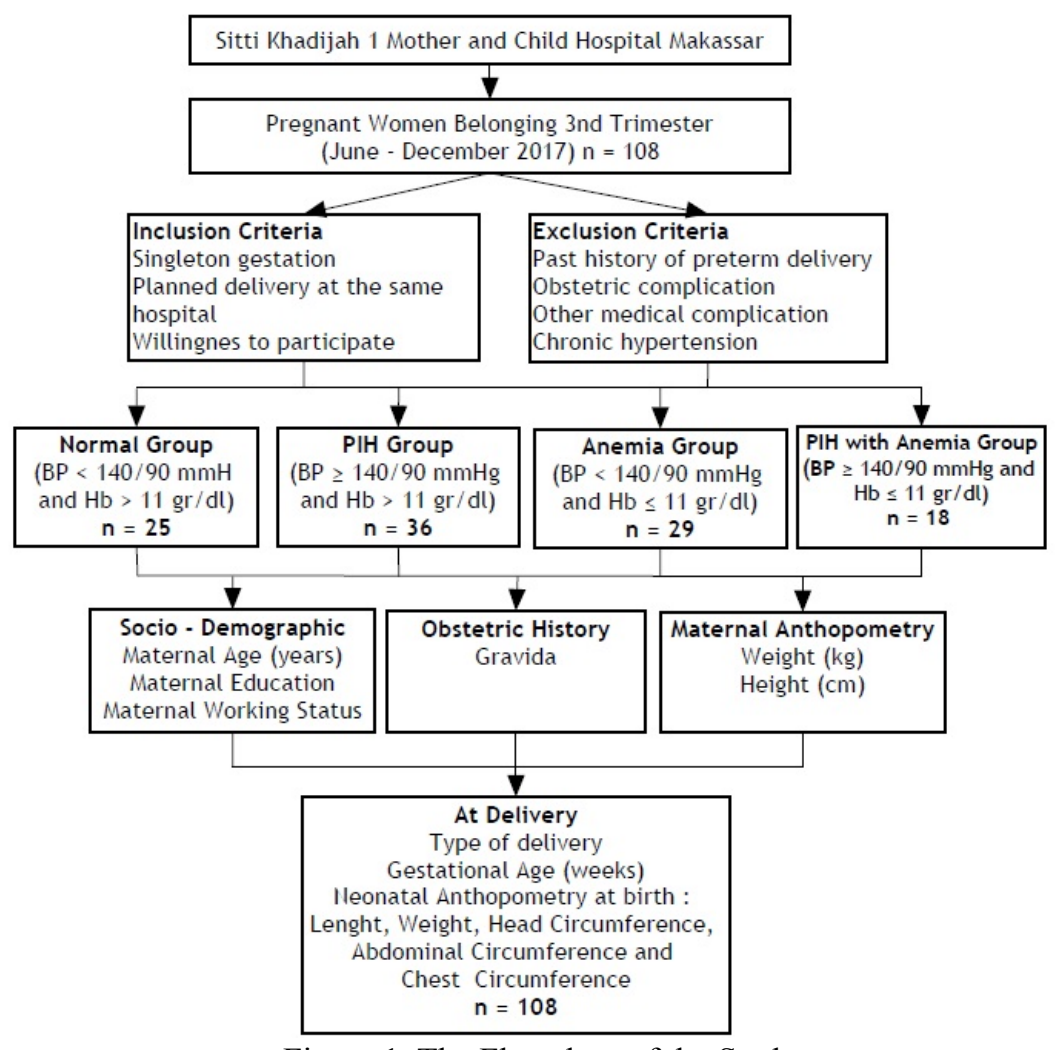

Figure 1. The Flowchart of the Study

\subsection{Data Collection}

On days during pregnant women, antenatal care checks, sociodemographic data, anthropometric and obstetric profiles were collected using questionnaires. Blood pressureswere measured using sphygmomanometery and maternal antopometric measurements (height and weight) were performed by the midwifes using the standardized techniques. $3 \mathrm{cc}$ blood samples were analyzed in the laboratory to check for the concentrations of $\mathrm{Hb}$. Types of delivery, gestational age, anthropometricof newborns (length, weight, head circumference, abdominal circumference and chest circumference) were measured at birth using the standardized techniques within 24 hours of birth. Length of newborn were measured using infantometer $(\mathrm{cm})$, weights of newborns were measuredusingan electronic baby scale (gr), and head, abdominal and chest circumference of newborns were measured using non-stretchable tapes $(\mathrm{cm})$. Neonates with birth weight at $<2500 \mathrm{gr}$ were classified in the low birth weight and newborns with length $<47 \mathrm{~cm}$ were classified as the stunting.

\subsection{Ethical Considerations}

This study received ethical clearance from the Research and Ethics Committee of Faculty of Medicine, Hasanuddin University and was registered in 1074/H4.8.4.5.31/PP36-KOMETIK/2017.

\subsection{Data Management and Analysis}

Descriptive analyses were presented as mean \pm standard deviation and frequencies for categorical variables. Bivariat analyses were analyzed and processed using Chi-Square test, ANOVA, Kruskal-Wallis test to determine the differences between all groups at 5\% level of significance.Spearman's correlation were used to determine further correlations. Data were analyzed using the Statistical Package for Social Science (SPSS) version 22 for Windows.

\section{Results}

\subsection{Sociodemographic and Maternal Anthropometric Profiles}

As indicated in Table 1, of 108 pregnant women, 25 pregnant women had normal conditions of blood pressure and normal $\mathrm{Hb}$ concentrations, 36 had hypertension, 29 had anemia and 18 had pregnancy induced hypertension (PIH) is accompaniedwith anemia during pregnancy. Level of education, working status, types of delivery and 
gestational age (GA)did not show statistically significant differences for each group, whereas, age, height, weight, body mass index $\left(\mathrm{BMI}: \mathrm{kg} / \mathrm{m}^{2}\right), \mathrm{Hb}$ concentration, systolic and diastolicblood pressure showed statistically significant differences for each group $(p=0.027 ; 0.019 ; 0.000 ; 0.001 ; 0.000,0.000 ; 0.000)$.

Table 1. Comparison of sociodemographic and anthropometric profile

\begin{tabular}{|c|c|c|c|c|c|}
\hline Variables & $\begin{array}{l}\text { Normal } \\
(n=25)\end{array}$ & $\begin{array}{l}\text { PIH } \\
(n=36)\end{array}$ & $\begin{array}{l}\text { Anemia } \\
(n=29)\end{array}$ & $\begin{array}{l}\text { PIH is accompanied Anemia } \\
(n=18)\end{array}$ & $p$-value \\
\hline \multicolumn{6}{|l|}{ Level of Education, n (\%) } \\
\hline Hingh & $12(21.8)$ & $20(36.4)$ & $13(23.6)$ & $10(18.2)$ & $0.806^{\mathrm{a}}$ \\
\hline Low & $13(24.5)$ & $16(30.2)$ & $16(30.2)$ & $8(15.1)$ & \\
\hline \multicolumn{6}{|l|}{ Working Status, n (\%) } \\
\hline Working & $13(25)$ & $19(36.5)$ & $13(25)$ & $7(13.5)$ & $0.752^{\mathrm{a}}$ \\
\hline Not Working & $12(21.4)$ & $17(30.4)$ & $16(28.6)$ & $11(19.6)$ & \\
\hline \multicolumn{6}{|l|}{ Gravida , n (\%) } \\
\hline Primiparous & $11(26.2)$ & $14(33.3)$ & $9(21.4)$ & $8(19)$ & $0.738^{\mathrm{a}}$ \\
\hline Multiparous & $14(21.2)$ & $22(33.3)$ & $20(30.3)$ & $10(15.2)$ & \\
\hline \multicolumn{6}{|l|}{ Type of Delivery, $n$ (\%) } \\
\hline Vaginal & $13(29.5)$ & $12(27.3)$ & $15(34.1)$ & $4(9.1)$ & $0.105^{\mathrm{a}}$ \\
\hline Cesarean section & $12(18.8)$ & $24(37.5)$ & $14(21.9)$ & $14(21.9)$ & \\
\hline Age (mean \pm SD) & $29.4 \pm 7$ & $32.47 \pm 6$ & $28.1 \pm 5.5$ & $31.17 \pm 4.9$ & $0.027^{\mathrm{b}}$ \\
\hline Height (mean \pm SD) & $152.28 \pm 5.8$ & $155.64 \pm 6$ & $155.03 \pm 5.5$ & $157.67 \pm 4.4$ & $0.019^{\mathrm{b}}$ \\
\hline Weight (mean \pm SD) & $61.3 \pm 8.8$ & $72.6 \pm 18.1$ & $62.9 \pm 8.8$ & $71 \pm 8.9$ & $0.000^{\mathrm{c}}$ \\
\hline $\mathrm{BMI}($ mean $\pm \mathrm{SD})$ & $26.5 \pm 4$ & $29.8 \pm 5.8$ & $26.2 \pm 3.75$ & $30.4 \pm 3.7$ & $0.001^{\mathrm{c}}$ \\
\hline $\mathrm{Hb}($ mean $\pm \mathrm{SD})$ & $12.4 \pm 0.7$ & $12.2 \pm 1$ & $9.8 \pm 0.9$ & $10 \pm 0.6$ & $0.000^{\mathrm{c}}$ \\
\hline $\mathrm{GA}($ mean $\pm \mathrm{SD})$ & $38.7 \pm 1.9$ & $37.8 \pm 1.9$ & $38.5 \pm 0.9$ & $34.4 \pm 1.4$ & $0.265^{\mathrm{c}}$ \\
\hline Systolic BP $($ mean \pm SD) & $112.4 \pm 8.8$ & $159.7 \pm 20.5$ & $115.2 \pm 7.4$ & $150.6 \pm 15.1$ & $0.000^{\mathrm{c}}$ \\
\hline Diastolic BP $($ mean \pm SD) & $76.4 \pm 6.3$ & $102.2 \pm 10.9$ & $75.9 \pm 6.3$ & $101.1 \pm 11.3$ & $0.000^{\mathrm{c}}$ \\
\hline
\end{tabular}

${ }^{\mathrm{a}}$ Chi Square; ${ }^{\mathrm{b}}$ ANOVA; ${ }^{\mathrm{c}}$ Kruskal-Wallis.

\subsection{Birth Outcomes of Newborns}

Mean length and weight of newborns were statistically significant lower in pregnancy induced hypertension (PIH) is accompaniedwith anemia $(p=0,001)$ [Table 2].

Table 2. Comparison of Birth Outcomes of Newborns

\begin{tabular}{llllll}
\hline $\begin{array}{l}\text { Variable } \\
(\text { Mean } \pm \text { SD) }\end{array}$ & $\begin{array}{l}\text { Normal } \\
(\mathbf{n}=\mathbf{2 5})\end{array}$ & $\begin{array}{l}\text { PIH } \\
(\mathbf{n}=\mathbf{3 6})\end{array}$ & $\begin{array}{l}\text { Anemia } \\
(\mathbf{n}=\mathbf{2 9})\end{array}$ & $\begin{array}{l}\text { PIH is accompanied Anemia } \\
(\mathbf{n}=\mathbf{1 8})\end{array}$ & $\boldsymbol{p}$-value \\
\hline Birth Length & $48,4 \pm 1,8$ & $46,3 \pm 3,3$ & $48,6 \pm 1,7$ & $46,8 \pm 2,3$ & $\mathbf{0 , 0 0 1}$ \\
Birth Weight & $3034 \pm 255,2$ & $2786 \pm 603,8$ & $3058,6 \pm 331,7$ & $2911,1 \pm 458,8$ & 0,268 \\
Abdominal Circumference & $31,3 \pm 1,7$ & $30,6 \pm 2,4$ & $31,4 \pm 1,8$ & $30,8 \pm 1,5$ & 0,654 \\
Chest Circumference & $31,8 \pm 1,1$ & $31,5 \pm 2,2$ & $32,2 \pm 1,7$ & $31,6 \pm 1,4$ & 0,620 \\
Head Circumference & $32,2 \pm 1,1$ & $32 \pm 2,3$ & $32,9 \pm 1,8$ & $32 \pm 1,5$ & 0,365 \\
\hline
\end{tabular}

Kruskal-Wallis Test. 


\subsection{Newborn Birth Length: Correlation and Association}

The correlationsbetween maternal $\mathrm{Hb}(\mathrm{gr} / \mathrm{dL})$, systolicblood pressure, diastolicblood pressure and birth anthropometry using Spearman's test showed negative correlation with birth length $(p=0.024 ; p=0.000 ; p=$ 0.000). Negative correlation means that if the systolicblood pressure, diastolic blood pressure and $\mathrm{Hb}$ increases, then the birth length of newborns will decrease.

Table 3. Correlationsbetween HaemoglobinConcentration, Sistolic Blood Pressure, Diastolic Blood Pressureand Birth Outcomes of Newborns

\begin{tabular}{llllll}
\hline Statistical Correlations & Birth Length & Birth Weight & Chest C. & Abdominal C. & Head C. \\
\hline \multirow{2}{*}{ Haemoglobin } & $r=-0.217$ & $r=-0.182$ & $r=-0.145$ & $r=-0.115$ & $\mathrm{r}=-0.173$ \\
& $p=0.024$ & $p=0.059$ & $p=0.134$ & $\mathrm{p}=0.237$ & $\mathrm{p}=0.074$ \\
Systole BP & $r=-0.379$ & $r=-0.174$ & $r=-0.156$ & $\mathrm{r}=-0.186$ & $r=-0.155$ \\
& $p=0.000$ & $p=0.071$ & $p=0.108$ & $p=0.054$ & $p=0.110$ \\
Diastole BP & $r=-0.360$ & $r=-0.166$ & $r=-0.124$ & $r=-0.115$ & $r=-0.132$ \\
& $p=0.000$ & $p=0.086$ & $p=0.201$ & $p=0.234$ & $p=0.172$ \\
\hline
\end{tabular}

Spearman's Test.

\section{Discussion}

This study showed that stunting in newborns occured in pregnant women with pregnancy induced hypertension $(\mathrm{PIH})$ and pregnancy induced hypertension $(\mathrm{PIH})$ is accompanied with anemia. In terms of risk factors, there were differences in age, weight, BMI, $\mathrm{Hb}$ concentration, systolic and diastolicblood pressure between normal group, pregnancy induced hypertension (PIH) group, anemia group and pregnancy induced hypertension (PIH) is accompaniedwith anemia group. Pregnant women with PIH had the highest mean of age (32 years) and the greatest score of weight $(72.6 \mathrm{~kg})$. Referring tothe mean body height and mean BMI, the group of pregnant women with pregnancy induced hypertension (PIH) is accompanied with anemia had the highest mean $(157.67 \mathrm{~cm})$ and $(30,4)$ compared to other group. Other studies have shown similar results that pregnant women with PIH were older than normal pregnant women (Qiu et al., 2007; Bilano et al., 2014; Ye et al., 2014; Muti et al., 2015; Townsend, O'Brien, $\&$ Khalil, 2016; Zhang et al., 2017; Berhe et al., 2018). Ages over 35 years and overweight are always associated with a risk of developing hypertension during pregnancy with ORs were 1.8; OR 2.39; OR 1.8 repectively (Ye et al., 2014; Townsend, O’Brien, \& Khalil, 2016).

Bivariate tests showed the birth outcomes of newborns, especially for the newborn's length in the normal group, pregnancy induced hypertension $(\mathrm{PIH})$, anemia and pregnancy induced hypertension $(\mathrm{PIH})$ is accompanied with anemia were significantly different $(p=0,001)$ with mean values of body lengthswere $48.4 ; 46.4 ; 48.6$ and 46.8 respectively. The correlation tests showed that there were negative correlations between hemoglobin level and length of newborn. It means that if the hemoglobin level increases, then length of newborns will be smaller. Another findings showed that there was no statistically difference in length of newborn of male sex in the mother with anemia dan normal hemoglobin(Gaur, 2015), but this finding is incompatible with other studiesin which normal hemoglobin leveles aremore likely to produce outcomes with normal anthropometry of newborns (Verhoeff et al., 2001; Ghimire \& Ghimire, 2013; Madaan et al., 2013; Kaur et al., 2015; Manthan, 2015; Tunkyi \& Moodley, 2017). These discrepancieswere supposed to be affectedby very small sample sizes and most of the samples had hypertension in pregnancy but not anemia.

Systolic and diastolic blood pressure also had a negative correlation with length of the newborn. It means that if the systolic and diastolic blood pressure increases, then length of newborn will be smaller, and these findings are in line with previous findings that blood pressure beyond normal limits in pregnant women lead to poor anthropometry in newborns including newborns with stunting conditions (Bilano et al., 2014; Kheir, Ali, \& Kononna, 2014; Muti et al., 2015; Irwinda, Raymond, \& Nembo, 2016; Khader et al., 2017; Ukah et al., 2017).

Results of the study showed that PIH condition gave more effects inlength of newborn length with $0,6 \mathrm{~cm}$ smaller than PIH is accompanied with anemia, but their mean length of newborn remained abnormal which called stunting $(<47 \mathrm{~cm})$. Although the mean length of newborn in PIH group $(46.3 \mathrm{~cm})$ was smaller than PIH is accompanied with anemia $(46.8 \mathrm{~cm})$ [Table 3], the PIH and anemia in preganant women could not be ignored because it could be 
used as two spectrums of pathological mechanisms that equally had an adverse effect on length of newborn.

Dietary intake is an important factor to the growth and development of newborns during the first 24 months of their life, hence nutritional dietary intake becomes an increasingly important factor afterwards (Investigators, 2017). The condition of newborn stunting is even associated with the poor life of children, and it couldincrease obesity and chronic diseases and the disruption of both both physical and psychic optimal growth and likely to have long-term harmful consequences in cognitive ability, school performance and will ultimately could give adverse effects to the development of a nation (Berkman et al., 2002; Grantham-McGregor et al., 2007; Victora et al., 2010; UNICEF, 2013; Danaei et al., 2016; Sinha et al., 2018). Therefore, it is suggested to enhance efforts to prevent the long-term adverse effects of newborn stunting by performing early and exclusive brestfeeding with on-time intake, high quality feeding and appropriate micronutrient interventions to their children (Jack \& Deborah, 2000; Danaei et al., 2016; Investigators, 2017; Sinha et al., 2018; Worku et al., 2018).

\section{Conclusion}

The average length of newborns in pregnant women with PIH and PIH is accompained with anemia was significantly significant shorter (stunting) than normal pregnant women. The presence of PIH and anemia arethe important predictors of the cause of newborn stunting. It is suggested that women who give birth with these conditions should pay more attention to the intake of good nutrition in the first 5 years of their children's life (the gold period) to prevent long-term adverse effects.

\section{Acknowledgements}

The authors would like to express their special thanks to the Director and staff of the Sitti Khadijah 1 for Mother and Child Health Makassar for their support and assistance.

\section{Competing Interests Statement}

The authors declare no conflict of interest.

\section{References}

Ahmed, M. A., Sharif, M. E., Rayis, D. A., Nasr, A. M., \& Adam, I. (2018). Hepatitis B infection and preeclampsia among pregnant Sudanese women.Virology Journal, 15(1), 20. https://doi.org/10.1186/s12985-018-0927-5

Asrie, F. (2017).Prevalence of anemia and its associated factors among pregnant women receiving antenatal care at Aymiba Health Center, northwest Ethiopia. Journal of blood medicine, 8, 35.https://doi.org/10.2147/JBM.S134932

Berhe, A. K., Kassa, G. M., Fekadu, G. A., \& Muche, A. A. (2018). Prevalence of hypertensive disorders of pregnancy in Ethiopia: a systemic review and meta-analysis. BMC pregnancy and childbirth, 18(1), 34.https://doi.org/10.1186/s12884-018-1667-7

Berkman, D. S., Lescano, A. G., Gilman, R. H., Lopez, S. L., \& Black, M. M. (2002). Effects of stunting, diarrhoeal disease, and parasitic infection during infancy on cognition in late childhood: a follow-up study. The Lancet, 359(9306), 564-571. https://doi.org/10.1016/S0140-6736(02)07744-9

Ota, E., Ganchimeg, T., Mori, R., \& Souza, J. P. (2014). Risk factors of pre-eclampsia/eclampsia and its adverse outcomes in low-and middle-income countries: a WHO secondary analysis. PloS one, 9(3), e91198. https://doi.org/10.1371/journal.pone.0091198

Chowdhury, H. A., Ahmed, K. R., Jebunessa, F., Akter, J., Hossain, S., \& Shahjahan, M. (2015). Factors associated with maternal anaemia among pregnant women in Dhaka city. BMC women's health, 15(1), 77. https://doi.org/10.1186/s12905-015-0234-x

Danaei, G., Andrews, K. G., Sudfeld, C. R., Fink, G., McCoy, D. C., Peet, E., ...\& Fawzi, W. W. (2016). Risk factors for childhood stunting in 137 developing countries: a comparative risk assessment analysis at global, regional, and country levels. PLoS medicine, 13(11), e1002164. https://doi.org/10.1371/journal.pmed.1002164

Endeshaw, G., \& Berhan, Y. (2015). Perinatal outcome in women with hypertensive disorders of pregnancy: a retrospective cohort study. International scholarly research notices, 2015. https://doi.org/10.1155/2015/208043

Feleke, B. E., \& Feleke, T. E. (2018). Pregnant mothers are more anemic than lactating mothers, a comparative cross-sectional study, Bahir Dar, Ethiopia. BMC Hematology, 18(1), 2. https://doi.org/10.1186/s12878-018-0096-1

Gaur, S., Kataria, S. K., \& Agarwal, R. (2015). A Study of Effects of Maternal Anaemia on Anthropometric 
Measurements of Newborns. The Pharma Innovation Journal, 4(8), 69-71.

Ghimire, R. H., \& Ghimire, S. (2013). Maternal And Fetal Outcome Following Severe Anaemia In Pregnancy: Results From Nobel Medical College Teaching Hospital, Biratnagar, Nepal. Journal of Nobel Medical College, 2(1), 22-26. https://doi.org/10.3126/jonmc.v2i1.7668

Grantham-McGregor, S., Cheung, Y. B., Cueto, S., Glewwe, P., Richter, L., Strupp, B., \& International Child Development Steering Group. (2007). Developmental potential in the first 5 years for children in developing countries. The lancet, 369(9555), 60-70. https://doi.org/10.1016/S0140-6736(07)60032-4

MAL-ED Network Investigators. (2017). Childhood stunting in relation to the pre-and postnatal environment during the first 2 years of life: The MAL-ED longitudinal birth cohort study. PLoS medicine, 14(10), e1002408. https://doi.org/10.1371/journal.pmed.1002408

Irwinda, R., Surya, R., \& Nembo, L. F. (2016).Impact of pregnancy-induced hypertension on fetal growth.Medical Journal of Indonesia, 25(2), 104. https://doi.org/10.13181/mji.v25i2.1381

Jack, P. S., \& Deborah, A. P. (2000).From Neurons to Neighborhoods The Science if Early Childhood Development, National Research Council Institute if Medicine.

Kaur, M., Chauhan, A., Manzar, M. D., \& Rajput, M. M. (2015). Maternal Anaemia and Neonatal Outcome: A Prospective Study on Urban Pregnant Women. Journal of clinical and diagnostic research: JCDR, 9(12), QC04. https://doi.org/10.7860/JCDR/2015/14924.6985

Khader, Y. S., Batieha, A., Al-njadat, R. A., \& Hijazi, S. A. S. (2018). Preeclampsia in Jordan: incidence, risk factors, and its associated maternal and neonatal outcomes. The Journal of Maternal-Fetal \& Neonatal Medicine, 31(6), 770-776. https://doi.org/10.1080/14767058.2017.1297411

Kheir, A. E., Ali, R. B., \& Kononna, A. A. (2014). Neonatal outcome in hypertensive disorders of pregnancy in a tertiary neonatal unit in Sudan. Journal of Medicine and Medical Research, 2(5), 59-65. Retrieved from www.resjournals.org/JMMR

Kolluru, V., Harika, R. Y., \& Kaul, R. (2016). Maternal and perinatal outcome associated with pregnancy induced hypertension. International Journal of Reproduction, Contraception, Obstetrics and Gynecology, 5(10), 3367-3371. https://doi.org/10.18203/2320-1770.ijrcog20163113

Madaan, G., Bhardwaj, A. K., Narang, S., \& Sharma, P. D. (2013). Effects of Third Trimester Maternal Hemoglobin Upon Newborn Anthropometry. Journal of Nepal Paediatric Society, 33(3), 186-189. https://doi.org/10.3126/jnps.v33i3.8251

Manthan, P., \& Poonam, P. (2015).Maternal anaemiaand its impact on perinatal outcome in tertiary care hospital. Int J Res Med, 4(4), 56-59.

Melamed, N., Ray, J. G., Hladunewich, M., \& Cox, B. (2014). Gestational hypertension and preeclampsia: are they the same disease?.Journal of Obstetrics and Gynaecology Canada, 36(7), 642-647. https://doi.org/10.1016/S1701-2163(15)30545-4

Muti, M., Tshimanga, M., Notion, G. T., Bangure, D., \& Chonzi, P. (2015). Prevalence of pregnancy induced hypertension and pregnancy outcomes among women seeking maternity services in Harare, Zimbabwe. BMC cardiovascular disorders, 15(1), 111. https://doi.org/10.1186/s12872-015-0110-5

Parmar, M. R., \& Vaja, P. (2017). Effect of pregnancy induced hypertension on maternal and perinatal outcome at tertiary care center in Ahmedabad, Gujarat, India. International Journal of Reproduction, Contraception, Obstetrics and Gynecology, 6(10), 4661-4665. https://doi.org/10.18203/2320-1770.ijrcog20174460

Patrícia Medeiros Falcão, K., Pedrozo Campos Antunes, T., do Nascimento Andrade Feitosa, A., Victor, E. G., Nunes Alves de Sousa, M., de Abreu, L. C., ... \& Azevedo de Freitas Junior, H. (2016). Association between hypertension and quality of life in pregnancy. Hypertension in pregnancy, 35(3), $306-314$. https://doi.org/10.3109/10641955.2016.1143485

Pels, A., \& Ganzevoort, W. (2015). Safety and efficacy of ferric carboxymaltose in anemic pregnant women: a retrospective case control study. Obstetrics and gynecology international, 2015. https://doi.org/10.1155/2015/728952

Perry, H., Sheehan, E., Thilaganathan, B., \& Khalil, A. (2018). Home blood - pressure monitoring in a hypertensive pregnant population. Ultrasound in Obstetrics \& Gynecology, 51(4), 524-530. https://doi.org/10.1002/uog.19023 
Qiu, C., Sanchez, S. E., Lam, N., Garcia, P., \& Williams, M. A. (2007). Associations of depression and depressive symptoms with preeclampsia: results from a Peruvian case-control study. BMC women's health, 7(1), 15. https://doi.org/10.1186/1472-6874-7-15

Roberts, J. M. et al. (2012).ACOG Guidelines: Hypertension in pregnancy, American College of Obstetricians and Gynecologists. https://doi.org/10.1097/01.AOG.0000437382.03963.88

Rogozińska, E., Marlin, N., Jackson, L., Bogaerts, A., Rayanagoudar, G., Ruifrok, A. E., ...\& Vinter, C. A. (2017). Effects of antenatal diet and physical activity on maternal and fetal outcomes: individual patient data meta-analysis and health economic evaluation. Health technology assessment, 21(41), 1-+. https://doi.org/10.3310/hta21410

Sabah, M. A., Ali, M. M., \& Adiba M, M. (2015).Effect of Maternal Hemoglobin on Anthopometric Measurements of Full Term Newly Born Babies. Iraqi Journal of Medical Sccience, 213(2), 137-142.

Saiki, M., \& Garovic, V. D. (2016). Hypertension and Pregnancy: Mechanisms and Management 1', Hypertension and Pregnancy. Mechanisms and Management Hypertension Journal, 2(3), 131-138. https://doi.org/10.5005/jp-journals-10043-0045.

Satyam, P., \& Khushbu, Y. (2015). Maternal Anemia in Pregnancy: An Overview. International Journal of Pharmacy \& Pharmaceitical Research, 2(2), 144-155. https://doi.org/10.3109/01460868309059842

Siddiqui, M. Z., Goli, S., Reja, T., Doshi, R., Chakravorty, S., Tiwari, C., ...\& Singh, D. (2017). Prevalence of Anemia and Its Determinants Among Pregnant, Lactating, and Nonpregnant Nonlactating Women in India. SAGE Open, 7(3), 2158244017725555. https://doi.org/10.1177/2158244017725555

Singh, S., \& Kaur, K. (2018). Maternal outcome in cases of severe anaemia in labour. International Journal of Reproduction, Contraception, Obstetrics and Gynecology, 7(3), 1201-1204. https://doi.org/10.18203/2320-1770.ijrcog20180918

Sinha, B., Taneja, S., Chowdhury, R., Mazumder, S., Rongsen - Chandola, T., Upadhyay, R. P., ... \& Bhan, M. K. (2018). Low - birthweight infants born to short - stature mothers are at additional risk of stunting and poor growth velocity: Evidence from secondary data analyses. Maternal \& child nutrition, 14(1). https://doi.org/10.1111/mcn.12504

Townsend, R., O’Brien, P., \& Khalil, A. (2016). Current best practice in the management of hypertensive disorders in pregnancy. Integrated blood pressure control, 9, 79. https://doi.org/10.2147/IBPC.S77344

Tunkyi, K., \& Moodley, J. (2017). Anemia and pregnancy outcomes: a longitudinal study. The Journal of Maternal-Fetal \& Neonatal Medicine, 1-5. https://doi.org/10.1080/14767058.2017.1349746

Ukah, U. V., De Silva, D. A., Payne, B., Magee, L. A., Hutcheon, J. A., Brown, H., ... \& von Dadelszen, P. (2017). Prediction of adverse maternal outcomes from pre-eclampsia and other hypertensive disorders of pregnancy: A systematic review. Pregnancy hypertension. https://doi.org/10.1016/j.preghy.2017.11.006

UNICEF. (2013). Improving child nutrition: the achievable imperative for global progress. https://doi.org/978-92-806-4686-3.

Verhoeff, F. H., Brabin, B. J., Van Buuren, S., Chimsuku, L., Kazembe, P., Wit, J. M., \& Broadhead, R. L. (2001). An analysis of intra-uterine growth retardation in rural Malawi. European Journal of Clinical Nutrition, 55(8), 682. https://doi.org/10.1038/sj.ejcn.1601200

Victora, C. G., de Onis, M., Hallal, P. C., Blössner, M., \& Shrimpton, R. (2010). Worldwide timing of growth faltering: revisiting implications for interventions. Pediatrics, peds-2009. https://doi.org/10.1542/peds.2009-1519

Worku, B. N., Abessa, T. G., Wondafrash, M., Vanvuchelen, M., Bruckers, L., Kolsteren, P., \& Granitzer, M. (2018).The relationship of undernutrition/psychosocial factors and developmental outcomes of children in extreme poverty in Ethiopia. BMC pediatrics, 18(1), 45. https://doi.org/10.1186/s12887-018-1009-y

Ye, C., Ruan, Y., Zou, L., Li, G., Li, C., Chen, Y., ... \& Zhang, W. (2014). The 2011 survey on hypertensive disorders of pregnancy (HDP) in China: prevalence, risk factors, complications, pregnancy and perinatal outcomes. PloS one, 9(6), e100180. https://doi.org/10.1371/journal.pone.0100180

Zhang, S., Wang, L., Leng, J., Liu, H., Li, W., Zhang, T., ... \& Hu, G. (2017). Hypertensive disorders of pregnancy in women with gestational diabetes mellitus on overweight status of their children. Journal of human hypertension, 31(11), 731. https://doi.org/10.1038/jhh.2017.17 


\section{Copyrights}

Copyright for this article is retained by the author(s), with first publication rights granted to the journal.

This is an open-access article distributed under the terms and conditions of the Creative Commons Attribution license (http://creativecommons.org/licenses/by/4.0/). 